\title{
1. Disability in refugee populations
}

\subsection{NAMING THE PROBLEM}

Natural disasters, wars and other forms of human conflict have caused death and disabilities for as long as human beings have lived in society. Disasters are, however, unequal in their impact: the very old, the very young, and the disabled are more likely to be killed or to sustain injuries. ${ }^{1}$ Refugees living with disabilities are often forgotten or invisible during acute crises of human displacement. They suffer multiple disadvantage. Exiled from their countries of nationality or origin, they live without the protection that comes with citizenship of, or habitual residence in, a state. They live in fear of persecution if returned to the country from which they have fled. ${ }^{2}$ Most significantly, they are hampered by physical, mental, intellectual or sensory impairments that, even in the best of times, would hinder their full and effective participation in society. ${ }^{3}$ Cut off from support networks in their home countries, they are also less likely to access

1 The earthquake and tsunami that struck in the Indian Ocean on 26 December 2004 killed over 230000 people in 14 countries. It was reported that four times as many women died as men; that one-third of all fatalities were children; but that persons with disabilities fared worst. See John Aglionby, 'Four times as many women died in tsunami', The Guardian, 26 March 2005. See, more generally, the research by Eric Neumayer and Thomas Plumper, 'The Gendered Nature of Natural Disasters: The Impact of Catastrophic Events on the Gender Gap in Life Expectancy' (2007) 551 Annals of the Association of American Geographers 97. That study examined disasters over 21 years.

2 See Article 1A(2) of the Convention relating to the Status of Refugees, opened for signature 28 July 1951, 189 UNTS 150 (entered into force 22 April 1954) ('Refugee Convention'); as amended by the Protocol relating to the Status of Refugees, opened for signature 31 January 1967, 606 UNTS 267 (entered into force 4 October 1967) ('Refugee Protocol').

3 See Article 1 of the Convention on the Rights of Persons with Disabilities, opened for signature 30 March 2007, 2515 UNTS 3 (entered into force 3 May 2008) ('CRPD'). See also Optional Protocol to the Convention on the Rights of Persons with Disabilities, opened for signature 30 March 2007, 46 ILM 443 (entered into force 3 May 2008) ('CRPD Optional Protocol'). The texts of both instruments are available online at http://www.ohchr.org/EN/HRBodies/CRPD/ Pages/ConventionRightsPersonsWithDisabilities.aspx (accessed 6 March 2017). 
aid after a disaster. Historically, legal frameworks have been inattentive to disability rights in general, but most particularly in relation to displaced persons.

It should take little imagination to realize the impact that displacement and deprivation will have on persons with disabilities, whenever and however their impairments are acquired. However, for too long, displaced persons with disabilities have been overlooked during and in the aftermath of disaster and conflict - especially when they cross borders as refugees. ${ }^{4}$ Whether a cause or symptom of this neglect, there seem to be assumptions that persons with disabilities do not survive disaster and that they do not travel. Our research confirms that neither of these assumptions is correct.

The World Health Organization (WHO) data indicates that 2.9 per cent of the world's total population comprise persons with severe disabilities, and that a further 12.4 per cent have moderate long-term disabilities. ${ }^{5}$ The United Nations High Commissioner for Refugees (UNHCR) - the agency charged with caring for the world's refugees - estimated that 65.3 million persons 'of concern' (such as asylum seekers, refugees and internally displaced persons (IDPs)) had been displaced from their homes by the middle of $2016 .{ }^{6}$ Applying the WHO estimates to the UNHCR figures suggests that at least 1.9 million displaced persons would have severe disabilities, and a further 8.1 million would have moderate long-term disabilities - a total of 10 million people.

The research for this book was undertaken because not enough is known about these people. In fact, there are still no reliable statistics on the incidence of disabilities amongst refugees, asylum seekers and IDPs, and existing registration systems do not capture the full range of physical and mental disabilities. Current research suggests a tendency to under-estimate the number of such persons with disabilities. Indeed such research as has been undertaken suggests that populations displaced by catastrophic events include a higher than usual number of persons with disabilities - as might be expected amongst people fleeing conflict or other violent or traumatic situations. In 2014, HelpAge International and Handicap International reported almost twice the WHO global average

4 Mary Crock, 'The protection of vulnerable groups' in Susan C Breau and Katja LH Samuel (eds), Research Handbook on Disasters and International Law (Cheltenham: Edward Elgar Publishing, 2016), 383.

5 WHO, The Global Burden of Disease: 2004 Update (Geneva: WHO, 2008), 34. See also WHO, World Report on Disability (Geneva: WHO and World Bank, 2011), Chapter 2.

6 UNHCR, 'Figures at a Glance', http://www.unhcr.org/en-au/figures-at-aglance.html (accessed 13 December 2016). 
in the number of persons with disabilities fleeing the conflict in Syria.? Researchers found 30 per cent of the Syrians interviewed had special needs, with impairments rising to 77 per cent for those categorized as 'aged'. ${ }^{8}$ There is also a lack of comprehensive data on how and when disabilities are acquired by displaced persons, disaggregated by sex, age and type of disability.

Crucially, little is known about the accommodations or adjustments (if any) that are made for these people, whether in refugee camps or among urban populations. No country can yet claim to fully apply the principles in the landmark United Nations Convention on the Rights of Persons with Disabilities (CRPD) ${ }^{9}$ to displaced persons. The same is often true of the many international and non-government organizations (NGOs) that assist displaced persons. While such organizations, as non-parties to treaties, do not formally bear human rights obligations under the CRPD, their practices and policies can profoundly impair or enable the fulfilment of CRPD rights.

This book has two aims. The first is to document what we have learned of the experiences of persons with disabilities living in displacement. The second is to explore the impact that the CRPD is having in humanitarian relief and assistance, and in longer term efforts to accommodate the needs of refugees with disabilities, particularly in the practice of states, international organizations and NGOs.

In this respect our work is 'applied' research. We acknowledge, nevertheless, that our methodologies and philosophical orientation align strongly with the equality and well-being theories propounded by Amartya Sen, ${ }^{10}$ Martha Nussbaum ${ }^{11}$ and others. ${ }^{12}$ We agree with their central

7 WHO (n 5), 8.

8 See HelpAge International and Handicap International, Hidden Victims of the Syrian Crisis: Disabled, Injured and Older Refugees (London: HelpAge International and Handicap International, 2014). Twenty per cent of the surveyed population has a physical, sensory or intellectual impairment and one in seven a chronic disease. One in 20 reported suffering from injury, with a majority of those injuries (nearly 80 per cent) resulting directly from the conflict.

9 See $\mathrm{n} 3$ above. See, for example, Arlene S Kanter, 'The Promise and Challenge of the United Nations Convention on the Rights of Persons with Disabilities' (2007) 34 (2) Syracuse Journal of International Law and Commerce 287.

10 Amartya K Sen, Development as Freedom (New York: Random House, 1999).

11 Martha C Nussbaum, Sex and Social Justice (Oxford: Oxford University Press, 1999).

12 See, for example, Marcia H Rioux, Lee Ann Basser and Melinda Jones (eds), Critical Perspectives on Human Rights and Disability Law (Boston: Martinus Nijhoff, 2011). 
proposition that justice and equality cannot be measured by apparent equality of opportunity. Both must be founded on concrete outcomes and achievements. Amartya Sen represents a natural starting point because of his articulation of two concepts that must combine to achieve human well-being in the context of justice and development. These are the notions of functioning and capability. Functioning describes the mechanical ways that human beings go about their lives. It is what people do and what they want to do and be. Examples include basic things like staying alive, obtaining sufficient nutrition, shelter and access to adequate healthcare. Functioning also extends to more complex achievements such as emotional happiness, pride and self-respect, and participating in social and political activities. ${ }^{13}$ The significance of adding 'capabilities' to any equation to measure well-being is that functions can be aspirational without the ability to actually put them into practice. In this respect capabilities align with freedom, or with the actual choices and options available to a person given his or her circumstances. ${ }^{14}$

Nussbaum builds on Sen's formulation of substantial freedom or 'capabilities' in her liberal theory of justice. She characterizes functionings as the right to be able to do basic and more complex things in society. Capabilities operate to illuminate what a person is actually able to achieve. ${ }^{15}$

As we explore in greater detail in Chapter 2, the paradigm shift embodied in the CRPD definition of disability captures perfectly the essence of the Sen and Nussbaum 'capabilities' approach. Rather than focusing on an individual's impairments, the Convention acknowledges that true disability involves both impairments and physical and intangible obstacles within a society that operate to prevent or impede an individual's participation. So it is that we set out not merely to 'count' or identify persons with disabilities living in displacement. Our objective rather was to understand the range of obstacles and challenges that operate to impede the functioning and participation in human society of refugees with disabilities.

Working closely with UNHCR and its implementing and operational partners across six countries, our qualitative research began in 2012 with fieldwork in Malaysia and Indonesia. In 2013, we turned our focus to Pakistan and Uganda. The final stage of the fieldwork in 2014 involved a case study of Syrian refugees living in border areas in Jordan and Turkey.

13 Sen (n 10), 75.

14 Ibid.

15 Nussbaum (n 11), 34. 
While many of these countries are not parties to the UN Convention relating to the Status of Refugees (the Refugee Convention) and its related Protocol, ${ }^{16}$ they are all parties to the CRPD. ${ }^{17}$ Documenting the experiences of refugees with disabilities living in each country, we sought to evaluate how various actors had responded or were responding to the CRPD's new paradigms. ${ }^{18}$

The project was designed to cover refugees living in a range of situations and under different conditions. As is typical of most refugees worldwide, most were 'urban refugees', living in cities or rural areas; others resided in government-controlled settlements; and yet others in refugee camps. Our interview subjects came from a variety of countries of origin. Some were recent arrivals and some had been in their host country since birth. In some countries, refugees were allowed to work and attend local schools. In others, they could not. The common feature in all the displacement contexts was the significant and multiple barriers faced by refugees because of their disabilities.

16 Uganda acceded to the Refugee Convention and its Protocol on 27 September 1976; Turkey ratified the Convention on 30 March 1962 and acceded to the Protocol on 31 July 1968 (with a geographic limitation). The remaining fieldwork countries are not signatories of the Convention or its Protocol. While not a party to the Convention, Jordan has constitutional protection for political refugees: Article 21 states 'Political refugees shall not be extradited on account of their political beliefs or for their defence of liberty': Constitution of the Hashemite Kingdom of Jordan 1952.

17 Malaysia ratified the CRPD on 19 July 2010, Indonesia ratified on 30 November 2011, Pakistan ratified on 5 July 2011, Uganda ratified on 25 September 2008, Jordan ratified on 31 March 2008 and Turkey ratified on 28 September 2009.

18 See our fieldwork reports: Mary Crock et al., 'Refugees and asylum seekers with disabilities: A preliminary report from Malaysia and Indonesia' (January 2015), https://www.researchgate.net/publication/281853950_Refugees_ and_Asylum_Seekers_with_Disabilities_A_Preliminary_Report_from_ Malaysia_and_Indonesia (accessed 6 March 2017); Laura Smith-Khan et al., 'Refugees with disabilities in Pakistan: An introductory report', University of Sydney, https://www.researchgate.net/publication/281854024_Refugees_with_ Disabilities_in_Pakistan_An_Introductory_Report (accessed 6 March 2017); Mary Crock et al., 'Protection of refugees with disabilities: Uganda fieldwork report, August-September 2013', University of Sydney, https://www.researchgate.net/publication/281853774_Protection_of_Refugees_with_Disabilities_ Uganda_Fieldwork_Report_August-September_2013 (accessed 6 March 2017); Mary Crock et al., 'Syrian refugees with disabilities in Jordan and Turkey', University of Sydney, https://www.researchgate.net/publication/281853465 Syrian_refugees_with_disabilities_in_Jordan_and_Turkey (accessed 6 March 2017). 


\subsection{STRUCTURE OF THE BOOK}

Our journey begins in Chapter 2 with a discussion of the Convention at the heart of our research. The CRPD is the Convention designed specifically to acknowledge the human rights of persons with disabilities. The practical import of the definition of disability in Article 1 of this instrument is the acknowledgement that impairments alone do not create disability. Rather, it is the failure to accommodate, to adapt and assist that 'disables'. The revolution wrought by the Convention is that it demands that persons with disabilities be treated as rights bearers rather than as persons suffering from medical problems: objects of pity or subjects of charity. The CRPD demands that persons with disabilities be afforded respect, dignity and assistance so as to facilitate their full participation in society. As we explore towards the end of this chapter, the CRPD and other international treaties require that UNHCR and its implementing and operational partners adopt procedures and services that respect the rights of refugees who have disabilities.

As a UN agency, UNHCR has acknowledged that the CRPD has implications for virtually every aspect of its policy and field operations from the collection of statistical information; the conduct of refugee status determinations; and the selection of refugees for resettlement; through to the treatment of refugees in camps and urban situations. Together with the International Committee of the Red Cross (ICRC), UNHCR is often one of the first agencies on the ground to offer relief in emergency displacement situations. As such it has been an organization designed as a relief agency, with modes of operation shaped very much by a medical and/or charity approach to disability. Having said this, the advent of the CRPD has been embraced by the agency. The CRPD has induced significant changes in UNHCR's institutional thinking, with serious implications for the design and implementation of field operations.

Of course, the CRPD is of recent provenance - and it operates as part of a matrix of international human rights instruments. For this reason, the discussion is followed by an overview of the international legal frameworks that have developed around disasters and disability in displacement. The rights regimes enshrined in international refugee law, international human rights law and international humanitarian law (IHL) provide conceptual structures that, together with the CRPD, are used throughout the book to organize discussion of our research findings.

In Chapter 3 we explain the various initiatives taken by UNHCR to transform its approach to persons with disabilities who fall within its mandate, care or control. UNHCR first acknowledged the CRPD and its application in displacement in its 2010 Executive Committee 'Conclusion 
on refugees with disabilities'. ${ }^{19}$ Since that time it has sought to implement its responsibilities with the publication of a Need to Know Guidance on working with refugees with disabilities ${ }^{20}$ and by revising various UNHCR tools. The agency continues to improve procedures for registering refugees and asylum seekers. Over the three years of the project the authors observed a marked change in attitude and approach to disability within this organization. Efforts made to revise handbooks and to create guidance notes demonstrate sensitivity to the paradigm shifts demanded by the CRPD. As we document, the changes within this agency have filtered gradually into the work of UNHCR's partners in the field.

As we explain in Chapter 3, the six fieldwork countries demonstrated the diversity in the experiences of refugees with disabilities around the world. If there is a sameness about the lived experience of severe deprivation and misery, it is also true that each displacement situation has unique features. In 2012, Malaysia hosted around 94000 refugees, intermingled with almost a million irregular migrants from Myanmar and other countries in its region. Indonesia was home to a much smaller number of refugees registered with UNHCR, as well as a modest population of undocumented asylum seekers hoping to transit to Australia by boat. In both of these countries, we saw little to no prospect of local integration for refugees.

Pakistan and Uganda support large groups of long-term refugee communities, mostly from neighbouring countries that have experienced ongoing conflict. Uganda processes asylum seekers and grants refugee status, while Pakistan takes a more laissez-faire approach. However the scale of cross-border movements (particularly from Afghanistan) has been such that most refugees and displaced persons in Pakistan are allowed to stay for long periods on a mandate or de facto basis. ${ }^{21}$ In both Uganda and Pakistan, local integration is facilitated and resettlement is used only in exceptional cases. Both host states face significant development challenges and rely on support from international partners.

Finally, the refugees we met in Jordan and Turkey were part of a large and ongoing influx from the crisis unfolding in Syria since 2011. While not granted official status, refugees in these two countries are referred to as 'guests' and are treated very generously by the host states. We undertook fieldwork at a time when the situation was transforming from a short-term

19 UNHCR Executive Committee, Conclusion on refugees with disabilities and other persons with disabilities protected and assisted by UNHCR, Conclusion No. 110 (LXI) (12 October 2010).

20 UNHCR, Need to Know Guidance: Working with Persons with Disabilities in Forced Displacement (Geneva: UNHCR, 2011).

21 See Chapter 3 below, and Laura Smith-Khan et al. (n 18). 
emergency into a more protracted displacement situation, punctuated by spasmodic surges of new arrivals. In all of the research countries we found examples of good practices, which emphasized the empowerment of refugees with disabilities and recognized the contributions they can make.

In some respects Chapter $\mathbf{4}$ goes to the heart of the research. It discusses how disabilities are identified within refugee populations. The questionnaire we developed to qualitatively interview refugees with disabilities in the research countries draws heavily on the International Classification of Functioning, Disability and Health (ICF). ${ }^{22}$ This is a conceptual approach adopted by the WHO, and subsequently by a group of international experts known as the Washington Group, that reflects the CRPD's emphasis on environmental factors as causative elements in the experience of disability. Rather than looking for impairments, the resulting ICFinspired surveys ask questions that embrace both impairments and access to assistance. For example, instead of asking 'Are you blind?', they ask 'Do you have difficulty seeing, even if wearing glasses?' ${ }^{23}$

Across all the countries we visited, UNHCR and its implementing partners are struggling to gauge the extent and nature of disabilities experienced by refugees and other persons of concern within UNHCR's mandate. Refugees with disabilities remain under-identified in most circumstances. Even where efforts are made to record the needs of refugees, less visible impairments - such as vision and hearing impairments, and mental illness - are likely to pass unnoticed. Our research suggests that the time constraints faced by UNHCR officials when first interacting with refugees do not explain entirely the failure to identify disabilities. We found that the use of either visual identification or self-reporting (a 'labelling' approach to impairments) tends to result in fewer cases being recorded. Where 'functionality' questions are used to register or survey a population, we found that data collected aligns more closely with the global averages estimated by the WHO.

What then, did we discover in our research? In Chapter 5 we suggest that the lived experience of refugees with disabilities may be much more complex and diverse than official records are able to capture. Perhaps unsurprisingly, across all locations we found a high incidence of persons experiencing psychosocial problems. Indeed, perhaps because these were so common, and resources so stretched, we found that psychological

22 WHO (n 5), 5.

23 See the Washington Group's Short Set of Questions, https://www.cdc. gov/nchs/data/washington_group/wg_short_measure_on_disability.pdf (accessed 6 March 2017). See Chapter 4 below for further discussion on the ICF and Washington Group approach. 
and psychosocial difficulties amongst refugee populations rarely rated a mention in data collected by UNHCR and its partner organizations. We also found it common for people to experience multiple impairments or functional difficulties, or to experience these alongside issues with pain, affect and fatigue. Unsurprisingly, again, we found that displacement conditions can contribute to the acquisition of disability. Irregular and exploitative work environments, poor living conditions and limited access to medical and social services can all lead to debilitating injuries and long term impairment.

Chapter 6 acts as a segue between the first and second parts of the book. In it we bring the discussion back to the conceptual foundation of the CRPD: that people experience disability through the interaction of personal characteristics and social, environmental and legal contexts. The chapter draws together the findings of earlier chapters, and introduces some of the key themes that are explored later in the book. It does this by considering how people with different impairments, of different ages, genders and from different cultural and linguistic backgrounds experience disability while living in displacement. The point is that different personal attributes intersect and change in different contexts so as to create differences in need and vulnerability. As the refugees in Uganda and the Syrian refugees in Jordan and Turkey demonstrated, experiences of war can lead to debilitating injuries that are carried into a country of refuge. Conditions in a host country can affect disability acquisition, as we observed in Malaysia. Irregular and exploitative work environments, poor living conditions, direct discrimination leading to assaults and limited access to medical services can all lead to injuries that endure as permanent impairments.

How disability is experienced is closely determined by context. People who have sight, hearing or speech impairments may find it easier to communicate if they have had access to education and are literate. The availability of technology (for example, voice-to-text, text-to-voice and other computer software) can greatly facilitate participation. Conversely, lack of access to education or technology can create substantial barriers. Lack of legal status can create major barriers to needed assistance, employment opportunities and education. Impairments can also exacerbate vulnerability to violence and other forms of abuse. As we explore in this chapter, people of different ages and genders experience disability differently. In Pakistan, older women were much more likely to have a disability than their male counterparts. In Uganda, older refugees with disabilities reported high levels of depression and anxiety, and feelings of exclusion. Gender-based social expectations can also present challenges. Men with disabilities faced discrimination due to their lack of access to 
stable employment. In some cases, women and children with disabilities risked abandonment, exclusion or abuse.

Part II of the book aligns our observational work with an analysis of the international laws and policies relevant to disability in displacement. It is here that we explore the intersections between the CRPD and the protective regimes of refugee, humanitarian and human rights laws. Chapter 7 begins this study by examining the effect the CRPD should be having on both the procedures used to determine refugee status under international law and the way in which the Convention definition of refugee is interpreted. The balance of Part II is then devoted to chapters that explore rights that should vest in persons with disabilities who are displaced by human conflict. These chapters are structured so as to follow the distinctions made in the Refugee Convention between persons who are 'merely present' on the territory of a state, compared with those whose relationship with a state deepens over time and/or by operation of law. In each instance we examine the interactions between the rights regime enshrined in the CRPD and the rights recognized in other protective schemes.

Chapter 8 opens with a discussion of the most fundamental protection rights enshrined in international law: those pertaining to security, personal integrity and human dignity, in the contexts of maritime interdiction and immigration detention. Here we engage, however briefly, with issues around disability and access to territory; the meaning and content of the obligation not to refoule or send back persons at risk; and the limitations placed on states' rights to detain non-citizens with disabilities who present as asylum seekers.

Chapter 9 turns then to examine law and practice surrounding the provision of humanitarian assistance to persons with disability affected by human conflicts. Our research suggests that refugees with disabilities face challenges in most aspects of life in all fieldwork locations. This starts with gaining access to basic food, shelter and healthcare. The services provided varied greatly across the different host countries. The experiences we document often reflect the broader development challenges present in each location. Predictably, we found that access to humanitarian assistance was often better in controlled camp settings, with urban refugees needing to be much more self-reliant. While significant challenges remain, efforts have been made in camps in both Jordan and Turkey to ensure the physical accessibility of facilities. In Uganda, accessibility is improved in both camp and urban locations through training of staff in disability issues, a reflection perhaps of the attention given to these issues at the highest levels of government.

Chapter 10 extends this discussion to address issues around more extended entitlements of persons in displacement in the search for durable 
solutions. ${ }^{24}$ Given the rights attaching to refugee status, this led us to examine the barriers faced by refugees with disabilities to full participation (integration) in their host societies. For children, this called us to examine access to education. For adults, we studied access to vocational training, employment and income generation. Finally, we considered community inclusion and - perhaps the ultimate symbol of local integration - access to naturalization. Refugees with disabilities face a number of barriers to full and equal participation in community, education and employment. Limited access to participation for all refugees (for example, through legal restrictions) can have a greater impact on those who have disabilities. Targeted initiatives with a focus on empowerment have proven a valuable way to overcome some of these barriers. Facilitation of self-representation through the creation of Disabled People's Oganizations (DPOs) for refugees has been a positive step in Uganda. Designing accessible buildings and providing transport assistance has been important in facilitating engagement of refugees with disabilities in Jordanian camps.

The book continues in Chapter 11 with an examination of the law and practice surrounding other durable solutions. Our research confirmed that the precarious nature of displacement can make all refugees more vulnerable to protection risks that can lead to disability. Further, as outlined in the preceding chapters, refugees with disabilities may face heightened protection concerns in displacement or find it more difficult to integrate. On the other hand, inclusive resettlement (where the refugee is accepted as a migrant in a third country) has traditionally been a major challenge. We found that work has been done within UNHCR to sensitize resettlement staff and make resettlement units and procedures more accessible. Even so, the policies of potential resettling states may still act as a barrier to resettlement for refugees with disabilities.

The book concludes in Chapter 12 with a discussion of how the CRPD might be used to improve policies, practices and outcomes for refugees with disabilities in displacement. In mapping the way forward, we can at least say with confidence that persons with disabilities do survive disasters and they do travel. Our research confirms that these people - even those with severe impairments - are well represented among those who flee home

24 UNHCR identifies three possible durable solutions for refugees to gain state protection: voluntary repatriation (if possible), where persons are able to regain national protection from their country of origin; local integration, where the host country can provide adequate national protection; or resettlement - where refugees are transferred to a third country that has agreed to admit them and offer them national protection through permanent residence status. See UNHCR, Resettlement Handbook (Geneva: UNHCR, 2011). 
and country to become refugees. In some cases, disability can contribute to the decision to flee, be it for treatment, or to avoid disability-specific persecution. Displacement can change the way disability is experienced, sometimes significantly.

In essence, our findings closely support the CRPD's conceptualization of disability. Far from being restricted to impairment, disability is truly the interaction of personal attributes with the social, legal and environmental context. The refugee experience presents a variety of challenges and sometimes opportunities, all of which have an impact on how different individuals experience disability. It is our hope that gaining a better understanding of this dynamic and complex reality will help address some of the potential barriers - and better capitalize on the opportunities - that displacement may present. 

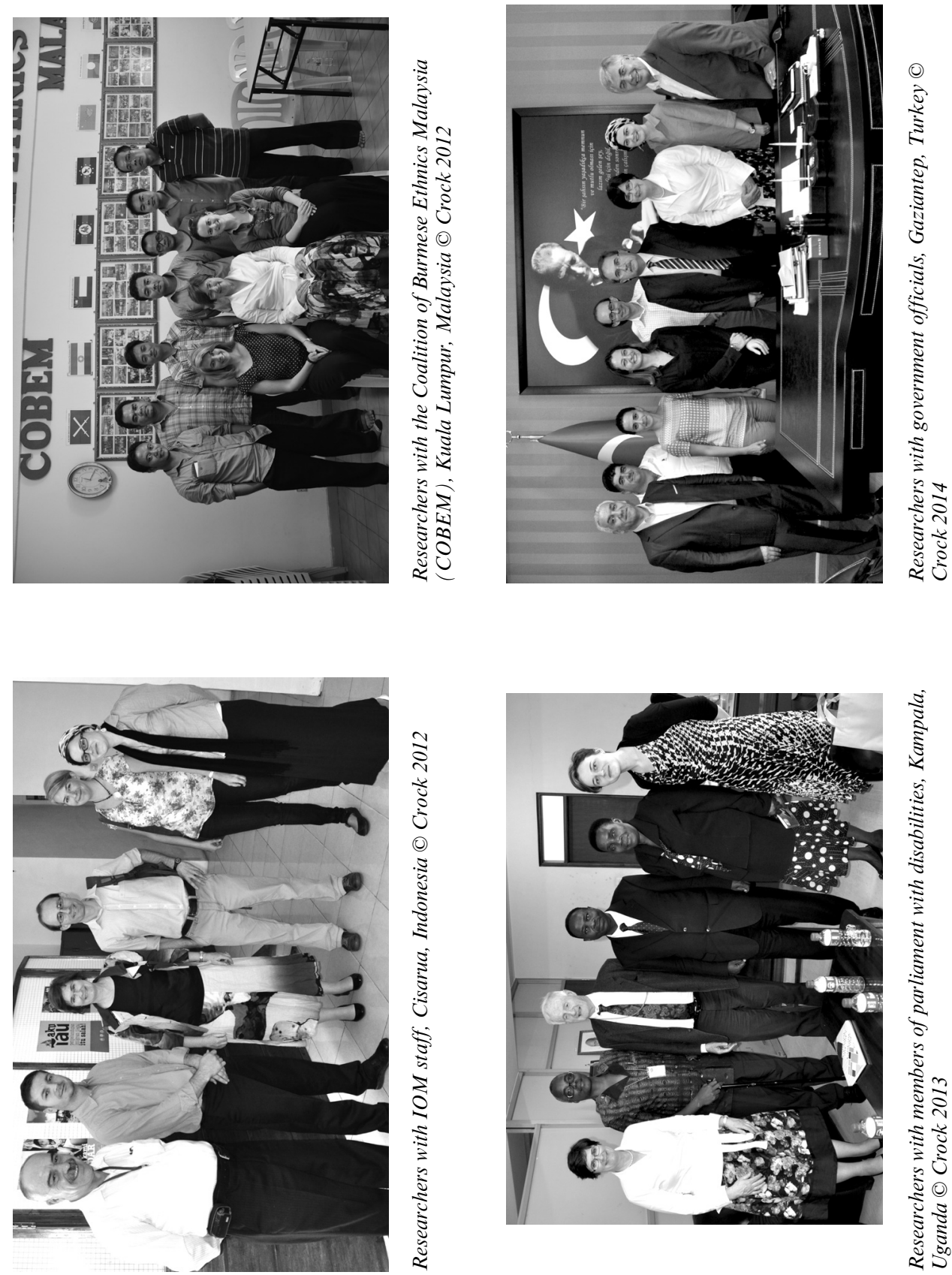

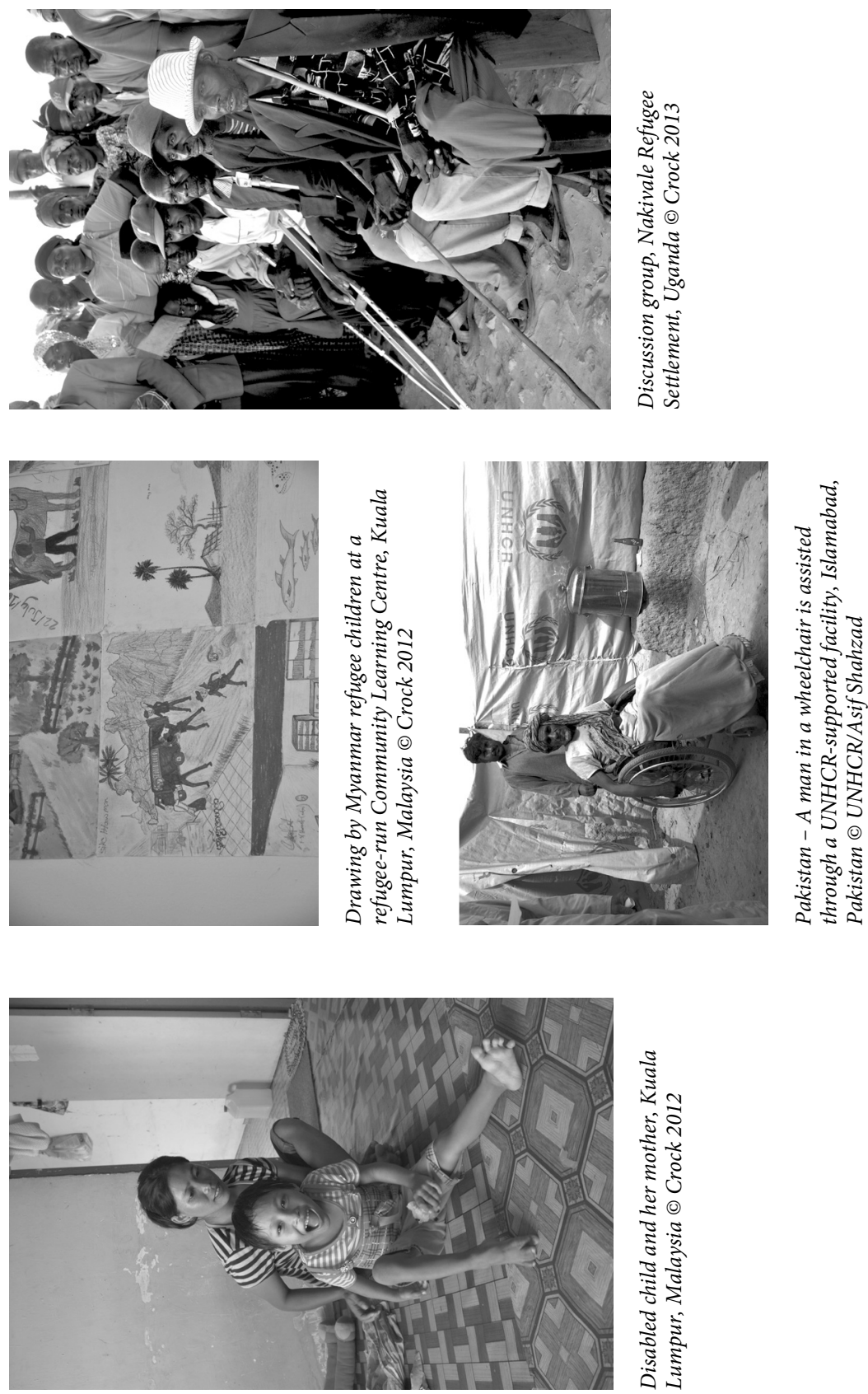